\title{
Correction: Deregulation of the pRb-E2F4 axis alters epidermal homeostasis and favors tumor development
}

\section{Clotilde Costa, Mirentxu Santos, Mónica Martínez-Fernández, Corina Lorz, Sara Lázaro and Jesús M. Paramio}

Copyright: Costa et al. This is an open-access article distributed under the terms of the Creative Commons Attribution License 3.0 (CC BY 3.0), which permits unrestricted use, distribution, and reproduction in any medium, provided the original author and source are credited.

Present: The grant support section is incomplete.

Correct: The complete grant support information appears below.

Original article: Oncotarget. 2016; 7:75712-75728. https://doi.org/10.18632/oncotarget.12362

\section{FUNDING}

This work was supported partially by funds from Fondo Europeo de Desarrollo Regional (FEDER) and by grants from the Ministry of Economy and Competitiveness of Spain ( ISCIII grants PI12/01959 and PI15/00993 to MS and MINECO grants SAF2012-34378 and SAF2015-66015-R) to JMP. Comunidad Autónoma de Madrid grant S2010/BMD- 2470 (Oncocycle Program), MSyC grant ISCIII-RETIC RD12/0036/0009 and PIE 15/00076 to JMP. MM-F was supported by Juan de la Cierva (JCI-2010-06167). 